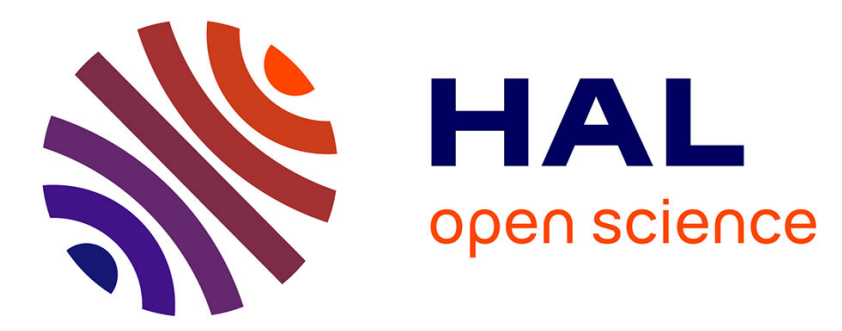

\title{
Binder-free preparation of ZSM-5@silica beads and their use for organic pollutant removal
}

Ping He, Jiehua Ding, Zhengxing Qin, Lingxue Tang, Kok-Giap Haw, Yiying Zhang, Qianrong Fang, Shilun Qiu, Valentin Valtchev

\section{- To cite this version:}

Ping He, Jiehua Ding, Zhengxing Qin, Lingxue Tang, Kok-Giap Haw, et al.. Binder-free preparation of ZSM-5@silica beads and their use for organic pollutant removal. Inorganic Chemistry Frontiers, 2020, 7 (10), pp.2080-2088. 10.1039/D0QI00259C . hal-03034298

HAL Id: hal-03034298

https://hal-normandie-univ.archives-ouvertes.fr/hal-03034298

Submitted on 9 Dec 2020

HAL is a multi-disciplinary open access archive for the deposit and dissemination of scientific research documents, whether they are published or not. The documents may come from teaching and research institutions in France or abroad, or from public or private research centers.
L'archive ouverte pluridisciplinaire HAL, est destinée au dépôt et à la diffusion de documents scientifiques de niveau recherche, publiés ou non, émanant des établissements d'enseignement et de recherche français ou étrangers, des laboratoires publics ou privés. 


\section{Journal Name}

\section{ARTICLE}

\section{Binder-free preparation of ZSM-5@silica beads and their use for organic pollutants removal}

Received 00th January 20xx, Accepted 00th January 20xx

DOI: $10.1039 / \times 0 \times x 00000 x$

www.rsc.org/
Ping He, ${ }^{a}$ Jiehua Ding, ${ }^{a}$ Zhengxing Qin, ${ }^{\text {b }}$ Lingxue Tang, ${ }^{\text {a }}$ Kok-Giap Haw, ${ }^{\text {a }}$ Yiying Zhang, ${ }^{\text {a }}$ Qianrong Fang, ${ }^{a}$ Shilun Qiu, ${ }^{a}$ Valentin Valtchev ${ }^{\mathrm{a}, \mathrm{c}^{*}}$

Zeolite is widely recognised as effective adsorbent for the removal of organic pollutants from aquous sources. However, its intrinsic powder form makes this application restricted by the arduous filtration-recovery process and decreased activity due to aggregation. Herein, we report an organic structure directing agent (OSDA) free and binder-free preparation of ZSM-5@silica beads for organic pollutants sequestration exemplified by the aniline removal. All silica beads were prepared by employing ion exchange resin beads as a macro template and further used to prepare ZSM-5@silica composite. First, anion exchange resin beads were charged with silica by ion exchange. Second, the anion exchange resin was eliminated by high temperature combustion leaving behind all-silica replica. The all-silica replica was partially transformed into ZSM-5 by hydrothermal treatment. ZSM-5 was synthesized from the organic template-free system, thus avoiding high temperature calcination of the composite. The effect of the crystallization temperature $\left(120,150\right.$, and $\left.170{ }^{\circ} \mathrm{C}\right)$ on the formation of ZSM5 was studied. The physicochemical properties of obtained beads were determined using different characterization methods such as powder X-ray diffraction (XRD), scanning-electron microscopy (SEM), $\mathrm{N}_{2}$ adsorption-desorption isotherms, and thermogravimetry (TG). The ZSM-5@silica composite demonstrated remarkable capacity outpacing most silica-based adsorbents and modified zeolitic materials, re-usability and retained spherical shape. The binder-free zeolite shaping technology offers a green and straightforward perspective of shaping zeolite-based adsorbents for the removal of organic pollutants from waste water.

Keywords: Zeolite@silica beads; binder-free; water decontamination; aniline

\section{Introduction}

Toxic organic pollutants existing in water sources and soil are harmful to organisms even at trace concentrations. ${ }^{1-3}$ Aniline from different origins, like petrochemical, dye and pharmaceutical industries, is one of the most common hazardous pollutants detected in nature. Thus, developing a highly efficient method to decontaminate aniline is urgently demand. ${ }^{4}$ In general, the sorption is the most versatile and promising method to treat intricate polluted water because of its high efficiency and the fact that it does not generate harmful byproducts. ${ }^{3,5}$

Various types of porous adsorbents have been employed

\footnotetext{
a. State Key Laboratory of Inorganic Synthesis and Preparative Chemistry, Jilin University, Changchun 130012, China.

b. State Key Laboratory of Heavy Oil Processing, College of Chemical Engineering,

China University of Petroleum (East China), Qingdao 266580, China.

c. Normandie Univ, ENSICAEN, UNICAEN, CNRS, Laboratoire Catalyse et

Spectrochimie, 6 Marechal Juin, 14050 Caen, France.

Email : valentin.valtchev@ensicaen.fr

Electronic Supplementary Information (ESI) available: [details of any supplementary information available should be included here]. See DOI: $10.1039 / \times 0 \times x 00000 x$
}

to sequestrate toxic aniline from waste water, ${ }^{6-9}$ like actived carbon, metal organic frameworks (MOFs), functionalized porous silica, and zeolites materials. Considering costeffective, available and regenerative features, zeolite is considered as an excellent sorbent for wastewater treatment. Zeolites offer orderly distributed and uniformly sized micropores, which determine selective adsorption of a target molecule. Moreover, its excellent thermal stability can withstand oxidative treatment even thermal regeneration of the adsorbent. ${ }^{10-12}$ Nano-adsorbents of different nature and high specific surface area demonstrate good potential in the field of sewage treatment. ${ }^{12-14}$ However, its practicability is significantly restricted by its arduous filtration-recovery process and decreased activity due to aggregation. ${ }^{15-18}$

Zeolites in shaped forms (granules, extrudates, pellets, beads), which combine convenient handling with efficient adsorption and facile separation, are highly desirable for decontamination of wastewater. ${ }^{19-21}$ Typically, a binder is used to construct a solid shaped body, requires several preparation steps, thus results in a more expensive product. ${ }^{16,22}$ The binder also decreases the adsorption capacity of zeolite body. However, the preparation of such bodies inevitably involves a special treatment, like surfactant modification, ${ }^{23}$ seeds coating, ${ }^{24}$ pseudomorphic transformation, ${ }^{25-27}$ and others, ${ }^{28-29}$ 
which gives more synthesis steps and needs skilled technique. In addition, most of them need expensive organic structure directing agent (OSDA), thus high temperature calcination is needed for removal of OSDA. The high temperature combustion is energy intense and environmental unfriendly step, which makes the product not cost-effective for water decontamination. ${ }^{30-34}$ Therefore, avoiding the use of OSDA in the preparation of shaped zeolite bodies is highly recommended. To the best of our knowledge, the preparation of binder-free micrometer sized ZSM- 5 beads in the absence of OSDA and seeds is not reported to date.

The objective of the present work is the preparation of OSDA- and binder-free ZSM-5@silica beads. The analysis of their physicochemical properties and the ability to adsorb organic pollutants is also an objective of the study. Aniline is employed as a target pollutant in order to evaluate the decontamination ability of the composite sorbents.

\section{Experimental}

\section{Materials:}

All reagents were obtained from commercial sources and used without further purification. Gel-type microporous anion exchange resin beads (Amberjet ${ }^{\circledR} 4200$, chloride-form), Sodium silicate (water glass) (26.5 wt\% $\mathrm{SiO}_{2}, 10.6$ wt\% $\mathrm{Na}_{2} \mathrm{O}$ and 62.9 wt\% $\mathrm{H}_{2} \mathrm{O}$ ) and Ludox $\mathrm{HS}-40$ (40 wt\% $\mathrm{SiO}_{2}$ ) were purchased from Sigma-Aldrich. Sodium hydroxide $(\mathrm{NaOH}, 98$ $\%)$ and Sodium aluminate $\left(\mathrm{NaAlO}_{2}, 98 \%\right)$ were purchased from Sigma-Aldrich. A Milli-Q integral ultrapure water system was employed to produce deionized (DI) water, which was used in all experiments.

\section{Synthesis of $\mathrm{SiO}_{2}$ beads:}

Microporous anionic exchange resin beads (Amberjet ${ }^{\circledR} 4200$ chloride-form) was employed as shaping templates for the preparation of silica beads. ${ }^{35}$ In a typical experiment, $2.0 \mathrm{~g}$ raw resin beads were mixed with $10 \mathrm{~mL}$ sodium silicate solutions and $90 \mathrm{~mL}$ deionized water. The ion exchange reaction was carried out in a silicon oil bath preheated to $100{ }^{\circ} \mathrm{C}$ for $6 \mathrm{~h}$ under reflux. After the reaction, the silicate-exchanged resin beads were separated from the liquid by suction filtration, subjected to ultrasonic treatment in deionized water to remove loosely attached silica species. After drying at $60{ }^{\circ} \mathrm{C}$ overnight, the resin-silicate composite was obtained. The resin beads were removed by calcination. The heating ramp was $1^{\circ} \mathrm{C}$ / $\mathrm{min}$ till $550^{\circ} \mathrm{C}$; then the beads were kept at $550{ }^{\circ} \mathrm{C}$ of $6 \mathrm{~h}$.

\section{Synthesis of ZSM-5@silica beads:}

All-silica beads were subjected to hydrothermal treatment in a ZSM-5 yielding system free of OSDA. The precursor gel with composition of $\mathrm{H}_{2} \mathrm{O}: \mathrm{SiO}_{2}: \mathrm{Na}_{2} \mathrm{O}: \mathrm{Al}_{2} \mathrm{O}_{3}=30: 1$ : 0.11 : 0.02 was prepared by dissolving Ludox $\mathrm{HS}-40, \mathrm{NaOH}, \mathrm{NaAlO}_{2}$ and $\mathrm{DI}$ water. After vigorous stirring overnight, the gel was transferred to an autoclave containing $\mathrm{SiO}_{2}$ beads. The ratio of gel: beads was 10: 0.5 in mass $\%$. The synthesis was performed in a rotating oven $(20 \mathrm{rpm})$ at $120,150,170{ }^{\circ} \mathrm{C}$ for $20 \mathrm{~h}$. The ZSM-5@silica beads were separated from the product formed in the bulk and ultrasonicated in DI water. The procedure was repeated several times until the $\mathrm{pH}$ value reached 7 . The composite beads were dried at $60{ }^{\circ} \mathrm{C}$ overnight. The obtained ZSM-5@silica beads were labelled as a function of synthesis temperature ZSB-120, ZSB-150, ZSB-170, respectively.

\section{Characterization:}

Powder X-ray diffraction (PXRD) analysis was performed on a PANalytical B.V. Empyrean powder diffractometer at $40 \mathrm{kV}$ and $40 \mathrm{~mA}$ using $\mathrm{Cu} \mathrm{Ka}$ radiation $(\lambda=1.5418 \AA$ ) in the range of $2 \theta=4.0-40.0^{\circ}$. A JEOL JSM-6510 scanning electron microscope equipped with EDX was used to study morphology and elemental analysis of the samples. Before PXRD analyses, the beads were ground into powder in an agate mortar. Thermogravimetric analysis (TGA) was performed on a SHIMADZU DTG-60 thermal analyzer system. Nitrogen adsorption analysis was performed on a Micromeritics ASAP 2460 volumetric adsorption analyzers with ultra-high-purity grade $\mathrm{N}_{2}(99.999 \%)$ at $77 \mathrm{~K}$. Prior to the analysis, the samples were degassed at $300{ }^{\circ} \mathrm{C}$ for $12 \mathrm{~h}$. The specific surface area of the beads was calculated using Brunauer-Emmett-Teller (BET) method within the relative pressure $\left(P / P_{0}\right)$ range of 0.05-0.25. The pore size distribution and total pore volume $\left(V_{\text {total }}\right)$ were determined from the adsorption branch using the density function theory (DFT). A SHIMADZU UV-2450 spectrophotometer was used to analyze the concentration of aniline during adsorption tests.

\section{Aniline decontamination test:}

In a batch experiment, $10 \mathrm{mg}$ beads were placed in a glass bottle containing $10 \mathrm{~mL}$ aniline solution with concentrations from 5 to $300 \mathrm{mg} \mathrm{L}^{-1}$, then shaken at room temperature with speed of $200 \mathrm{rpm}$ for $12 \mathrm{~h}$. The residual concentration of aniline was determined using a UV spectrophotometer at the corresponding maximum absorption wavelength $(286 \mathrm{~nm})$. The adsorbed amount was calculated from the equation $\mathrm{q}_{\mathrm{e}}=\mathrm{V}$ $\left(C_{0}-C_{e}\right) / m$, where $q_{e}$ is the equilibrium amount adsorbed ( $\mathrm{mg}$ $\left.\mathrm{g}^{-1}\right), \mathrm{V}$ is the volume of the liquid phase $(\mathrm{L}), \mathrm{C}_{0}$ and $\mathrm{C}_{\mathrm{e}}$ are the initial and the equilibrium concentration of aniline solution $\left(\mathrm{mg} \mathrm{L}^{-1}\right)$, respectively, and $\mathrm{m}$ is the mass of the adsorbent $(\mathrm{g})$. All adsorption experiments were repeated three times to ensure an adequate reproducibility.

\section{Results and discussion}

\section{Structure and morphology analysis}

Anionic exchange resin beads with gel-type microporous structures were chosen as a hard template, and silicate species originating from a sodium silicate solution were introduced within the resin structure by ion exchange. After resin combustion, $\mathrm{SiO}_{2}$ beads with a shape and size similar to that of resin beads were obtained. The obtained $\mathrm{SiO}_{2}$ beads were subjected to hydrothermal treatment with ZSM-5 yielding gel, which did not contain an OSDA. Figure 1 presents the XRD patterns of the initial $\mathrm{SiO}_{2}$ beads and ZSB-120, ZSB-150 and ZSB-170 composites. The $\mathrm{SiO}_{2}$ beads are amorphous, while the 
hydrothermally treated ones contain ZSM-5. The ZSM-5 amount depends on the crystallization temperature. Thus, a small amount of crystalline phase is detected in the ZSB-120 sample. The ZSM-5 peaks are more intense in ZSB-150. As for ZSB-170, the crystallinity is higher compared with the ZSB-150 sample. The mother liquor from ZSB-120 and ZSB-150 synthesis system does not contain crystalline material (Figure S1), which indicates that the crystallization of ZSM-5 on the silica beads outpaces the formation of the zeolite in the bulk solution. The only exception is ZSB-170, where ZSM-5 formed in the bulk liquor due to the faster crystallization kinetics at this temperature. The broad peak, with a maximum at about $2 \theta \approx 22^{\circ}$ indicates the presence of amorphous $\mathrm{SiO}_{2}$ in all samples, i.e., the silica beads were not fully converted into the zeolite. In summary, the ZSM-5 growth is strongly influenced by the synthesis temperature in the OSDA-free system. At low temperature $\left(120^{\circ} \mathrm{C}\right)$, there is only a trace of ZSM-5 on the surface of silica beads. The raise of crystallization temperature to $150{ }^{\circ} \mathrm{C}$ resulted in more abundant formation of ZSM-5 on the beads, but no crystalline phase was found in the bulk solution. Further increasing of the synthesis temperature (170 ${ }^{\circ} \mathrm{C}$ ) resulted in ZSM-5 formation in both, the silica beads and the bulk solution. It means silica beads plays an important role in accelerating the crystallization process in this OSDA-free system.
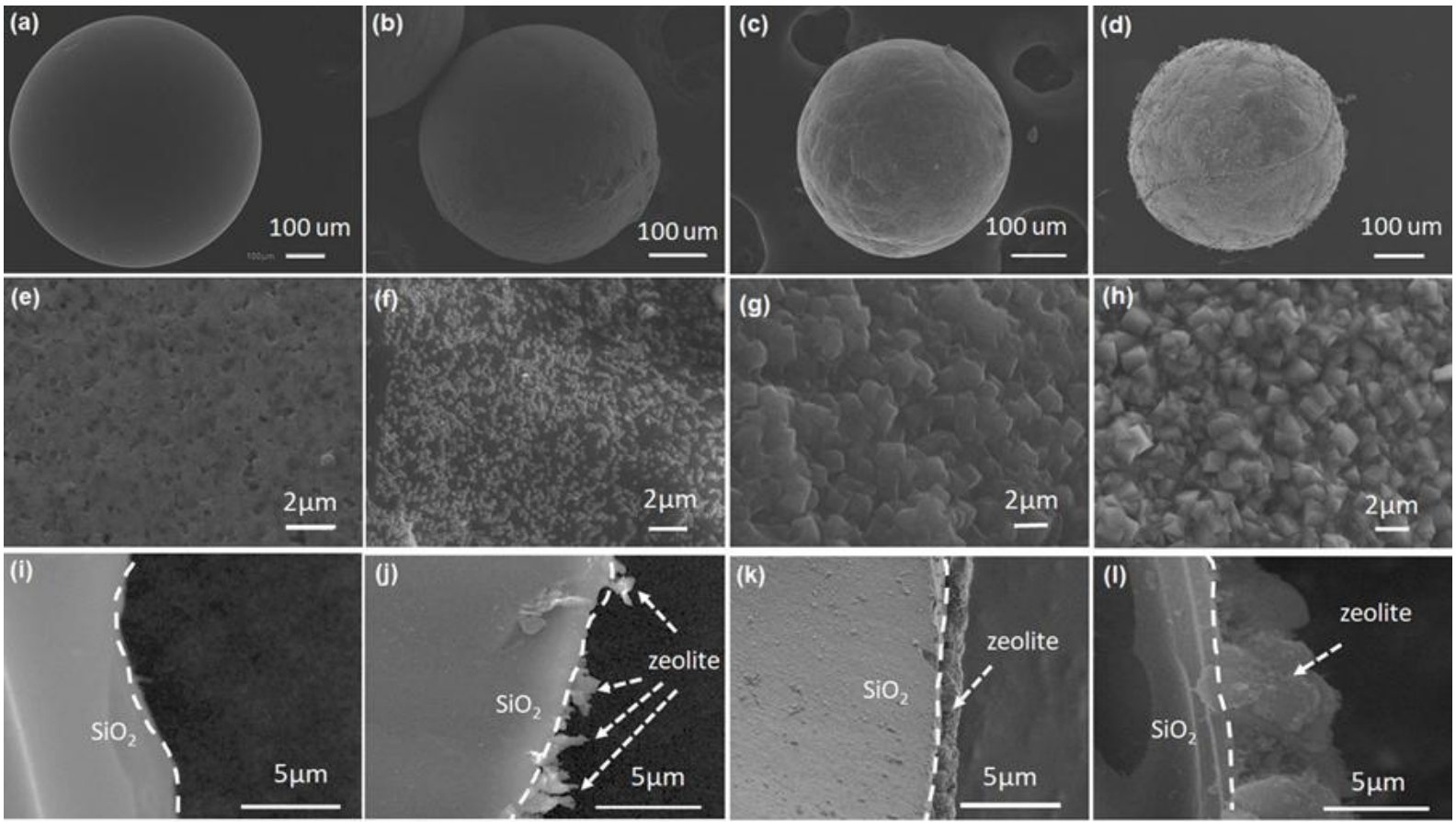

Figure 2. General view (a-d), external surface (e-h) and cross section (i-l) SEM micrographs of $\mathrm{SiO}_{2}(\mathrm{a}, \mathrm{e}, \mathrm{i}), \mathrm{ZSB}-120(\mathrm{~b}, \mathrm{f}, \mathrm{j}), \mathrm{ZSB}-150$ (c, g, k), and ZSB-170 (d, h, l) beads. 
Representative optical photographs and SEM micrographs of the obtained $\mathrm{SiO}_{2}$ and ZSB-120, 150 and 170 beads are shown in Figure S2 and Figure 2. The $\mathrm{SiO}_{2}$ and $\mathrm{ZSBs}$ beads all preserve their spherical morphology. The surface of silica beads is smooth (Figure 2a) built up of uniform particles (Figure 2e, i). Isolated ZSM-5 crystallites in size 100-200 nm can be found at the surface of the ZSB-120 sample (Figure $2 b$, $f, j)$. Well-intergrown and continuous zeolite ZSM-5 shell is formed in the case of ZSB-150 (Figure 2c, g). It is difficult to distinguish the individual crystals due to their small size. The thickness of the shell is about $1 \mu \mathrm{m}$ (Figure 2k). Also, wellintergrown but discontinues ZSM-5 shell was observed in the case of ZSB-170 (Figure 2d, h), the top layer is built of wellshaped crystallites with thickness in 3-5 um (Figure $2 \mathrm{~h}, \mathrm{l}$ ). Moreover, ZSM- 5 crystals collected from the bulk solution and denoted BS-170 show the characteristic of ZSM-5 coffin morphology (Figure S3). This phenomenon can be interpreted that the nucleus at $170{ }^{\circ} \mathrm{C}$ with beads is affected by its mother solution, resulting in the discontinuous morphology on the layer. Zeolite nucleation is a heterogeneous process where foreign surfaces play an important role, the surface of silica beads was dissolved and converted to intergrown ZSM-5 layer, forming core-shell zeolite composites. ${ }^{36}$ Precisely, higher concentration of silicon species on the beads prompting the zeolite formation precedes that in the bulk mother liquor. Chemical composition of the formed beads was studied by EDX analysis (Table S1). Only silicon and a small amount of sodium were detected in the initial silica beads. The Si/Al ratio of ZSB120 is relatively high (ca. 20), since the result is influenced by all silica beads laying below the thin ZSM-5 shell. The Si/Al ratio in the ZSB-150 and ZSB-170 is about 15, which is reasonable for template-free synthesized ZSM-5. ${ }^{31-32}$

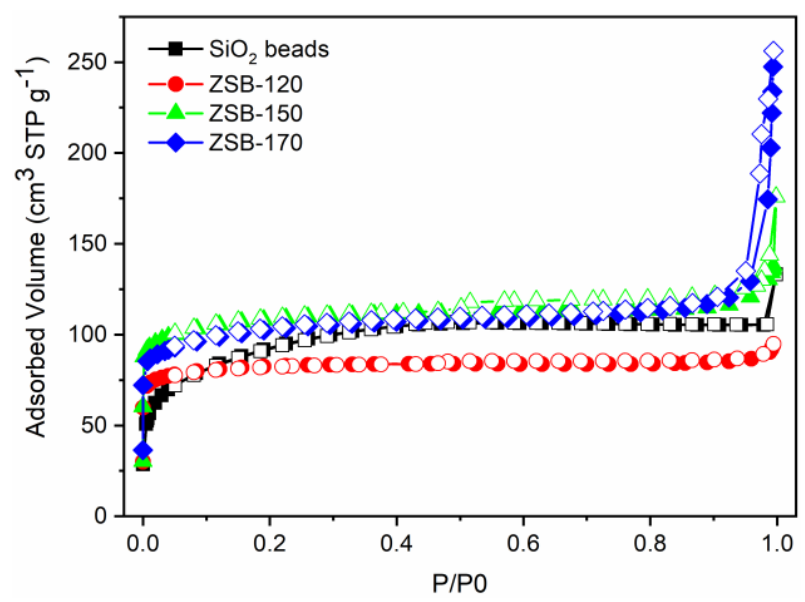

Figure 3. Nitrogen sorption isotherms of $\mathrm{SiO}_{2}$, ZSB-120, ZSB-150, ZSB170 beads. Note: adsorption - full symbols; desorption - empty symbols.
Table 1. Surface and porous characteristics of the obtained beads

\begin{tabular}{|c|c|c|c|}
\hline Sample & $\mathrm{S}_{\mathrm{BET}}\left(\mathrm{m}^{2} \mathrm{~g}^{-1}\right)$ & $V_{\text {total }}\left(\mathrm{cm}^{3} \mathrm{~g}^{-1}\right)$ & $V_{\text {micro }}\left(\mathrm{cm}^{3} \mathrm{~g}^{-1}\right)$ \\
\hline $\mathrm{SiO}_{2}$ beads & 289 & 0.16 & 0.06 \\
\hline ZSB-120 & 287 & 0.14 & 0.10 \\
\hline ZSB-150 & 361 & 0.21 & 0.13 \\
\hline ZSB-170 & 345 & 0.32 & 0.11 \\
\hline
\end{tabular}

The nitrogen adsorption-desorption isotherms of the beads are presented in Figure 3, and the DFT pore size distributions in Figure S4. All the isotherms showed a steep uptake at low pressure region, typical of a microporous material, which conforms to type I isotherm according to the IUPAC classification. The hysteresis loop at high relative pressure is a consequence of the presence of large mesopores. The isotherm of $\mathrm{SiO}_{2}$ beads is different; the uptake at low relative pressure is small and followed by the inclination of the isotherm revealing the presence of mesopore with different sizes. The surface and porous characteristics calculated from the analysis of the isotherms are summarized in Table 1 . All ZSB samples show a micropore volume higher than the $\mathrm{SiO}_{2}$ beads. The micropore volume of the ZSM-5@silica beads obtained at 150 and $170{ }^{\circ} \mathrm{C}$ is higher which correlates with the higher zeolite content (Table 1 ). We attribute this result to the partial transformation of silica beads into zeolite and the generation of additional micro porosity in the silica matrx. ${ }^{37-38}$ The XRD diffraction data of ZSB-150 and ZSM-170 (Figure 1) are in agreement with this conclusion.

Thermal analysis was employed to evaluate the impact of hydrothermal treatment on the all-silica and ZSB beads (Figure S5). The most significant weight loss is between 25 and $450{ }^{\circ} \mathrm{C}$ observed for all beads, which is due to the water release and dehydroxylation of the silica and zeolite framework. ZSB-120 shows slightly higher weight loss in respect of the $\mathrm{SiO}_{2}$ beads. The release amount is again higher in ZSB-150 and ZSB-170 samples, which is a function of the zeolite content in the beads. Thus, the TG analysis confirm the results from the XRD and $\mathrm{N}_{2}$ adsorption analyses.

\section{Aniline adsorption from aqueous solution}

The all-silica and zeolite@silica beads were tested in the decontamination of aqueous aniline-containing solutions. Absorption spectra with various concentrations of aniline were recorded to prepare the standard curves (Figure S6). The molecular size of aniline is $0.59 \mathrm{~nm}$, which is close to the opening pore of the ZSM-5. There is the so-called close-fit theory, zeolite shows distinct adsorption affinity to molecules with close pore size. ${ }^{39-41}$ Moreover, acid-base interactions between the amino-group of aniline and Brønsted acid sites in 

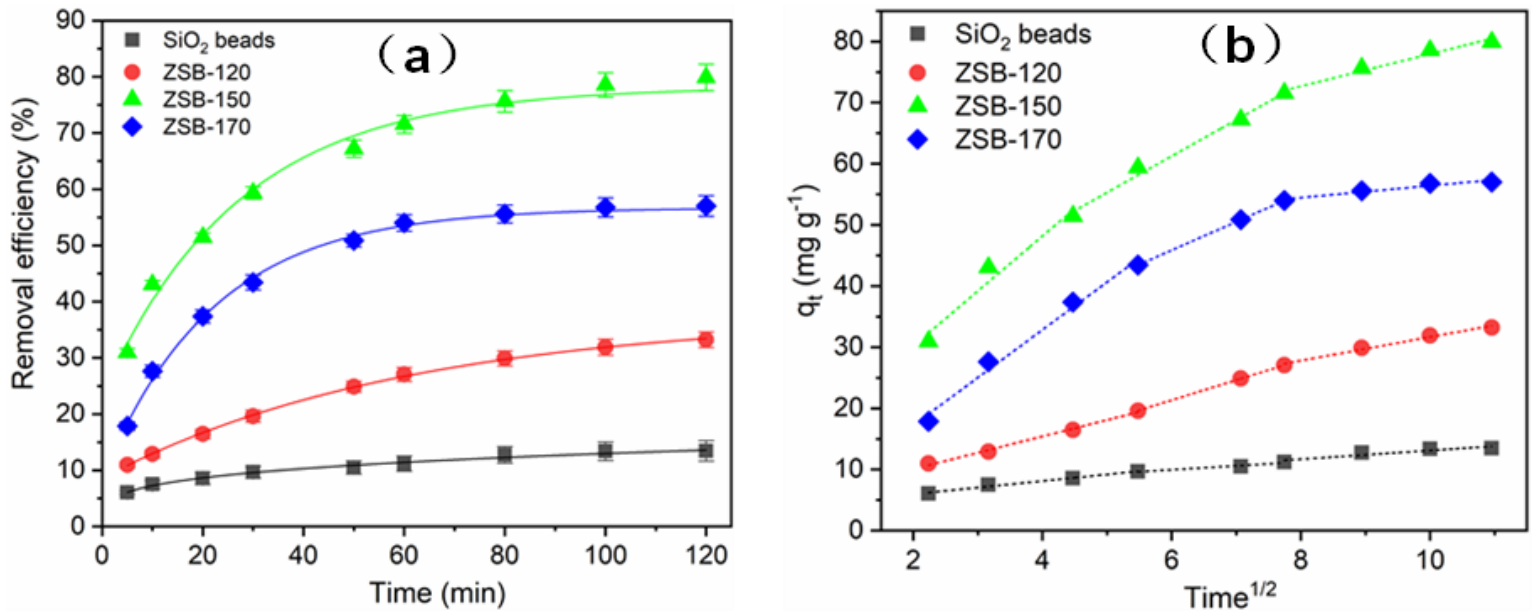

Figure 4. The adsorbed amount of aniline(a) and Intra-particle diffusion plots of aniline (b) on the obtained $\mathrm{SiO}_{2}, \mathrm{ZSB}-120, \mathrm{ZSB}-150, \mathrm{ZSB}-170$ beads (adsorption temperature: $25^{\circ} \mathrm{C}, \mathrm{Co:} 20 \mathrm{mg} \mathrm{L}^{-1}$, adsorbent: $1 \mathrm{~g} \mathrm{~L}^{-1}$ ).

zeolite@silica beads also contribute to the adsorption performance. ${ }^{42}$ Thus the size-dependent interaction and acidbase interactions between the targeted pollutant and the zeolite-containing beads is expected to provide a highly selective and efficient removal property for aniline.

The sorption kinetics of aniline over the beads as a function of contact time was studied (Figure 4a). The uptake was fast in the first $20 \mathrm{~min}$, owing to the abundantly available adsorption sites. Then, the adsorption rate gradually slowed down and reached equilibrium after $90 \mathrm{~min}$. The series of ZSB beads showed significantly enhanced sorption capacity toward aniline compared with $\mathrm{SiO}_{2}$ beads. This result was related to the high selectivity of the zeolite to the aniline. The ZSB-150 beads demonstrated the highest aniline removal capacity, although this sample contains less zeolite than ZSB-170. We attribute this result to the good balance between zeolite content and accessibility in this composite. In other words, as explained by the diffusion-adsorption model, the formation of a large amount of intergrown ZSM-5 in ZSB-170 probably has a negative impact on the aniline diffusion and decreases the adsorption capacity. ${ }^{23,} 43-44$ Therefore, the subsequent adsorption experiments were performed with ZSB-150 and allsilica beads.
The obtained data were used to build mathematical models using pseudo-first-order and pseudo-second-order equations: $\ln \left(\mathrm{q}_{\mathrm{e}}-\mathrm{q}_{\mathrm{t}}\right)=\ln \mathrm{q}_{\mathrm{e}}-\mathrm{k}_{1} \mathrm{t}$ and $\mathrm{t} / \mathrm{q}_{\mathrm{t}}=1 / \mathrm{k}_{2} \mathrm{q}_{\mathrm{e}}{ }^{2}+\mathrm{t} / \mathrm{q}_{\mathrm{e}}$, where $\mathrm{q}_{\mathrm{t}}\left(\mathrm{mg} \mathrm{g}^{-1}\right)$ and $\mathrm{q}_{\mathrm{e}}\left(\mathrm{mg} \mathrm{g}^{-1}\right)$ are the adsorption capacities at any time and equilibrium, respectively. The $\mathrm{k}_{1}\left(\mathrm{~min}^{-1}\right)$ and $\mathrm{k}_{2}$ $\left(\mathrm{g} \mathrm{mg}^{-1} \mathrm{~min}^{-1}\right.$ ) represent the constants of the pseudo-firstorder and pseudo-second-order rates, respectively. The simulated data are shown in Figure S7 and the corresponding parameters calculated from the models are listed in Table 2. All values of correlation factor $\left(R^{2}\right)$ obtained from the plots of pseudo-second-order kinetics are greater $\left(R^{2}>0.98\right)$, indicating that the adsorption kinetics of aniline on the studied adsorbent fits well with this model. It also showed that the calculated $\mathrm{q}_{\mathrm{e}}$ values are well-accorded with the actual experimental values, and the adsorption towards aniline almost reached equilibrium in $2 \mathrm{~h}$. Similar results were reported for the aniline adsorption on different adsorbents. ${ }^{6,45}$

The equation $q_{t}=k_{i d} t^{1 / 2}+C$, was used to study the

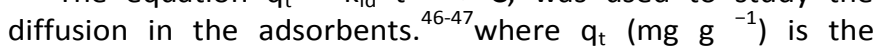
adsorption

Table 2. Kinetic parameters of aniline adsorption on different beads at $25^{\circ} \mathrm{C}$ from solution with $20 \mathrm{mg} \mathrm{L}^{-1}$ concentration

\begin{tabular}{|c|c|c|c|c|c|c|}
\hline \multirow[b]{2}{*}{ Adsorbents } & \multicolumn{3}{|c|}{ Pseudo-first-order kinetic model } & \multicolumn{3}{|c|}{ Pseudo-second-order kinetic model } \\
\hline & $\begin{array}{l}\mathrm{q}_{\mathrm{e}}, \\
\mathrm{mg} \mathrm{g}^{-1}\end{array}$ & $\begin{array}{l}\mathrm{k}_{1} \\
\min ^{-1}\end{array}$ & $\mathrm{R}^{2}$ & $\begin{array}{l}\mathrm{q}_{\mathrm{e}} \\
\mathrm{mg} \mathrm{g}^{-1}\end{array}$ & $\begin{array}{l}\mathrm{k}_{2} \\
\mathrm{~g} \mathrm{mg}^{-1} \mathrm{~min}^{-1}\end{array}$ & $\mathrm{R}^{2}$ \\
\hline $\mathrm{SiO}_{2}$ & 15.4464 & 0.0139 & 0.9762 & 14.614 & 0.0053 & 0.9888 \\
\hline ZSB-120 & 39.2285 & 0.0139 & 0.9952 & 38.461 & 0.0012 & 0.9842 \\
\hline ZSB-150 & 85.8940 & 0.0191 & 0.9833 & 86.957 & 0.0009 & 0.9977 \\
\hline ZSB-170 & 61.0261 & 0.0214 & 0.9328 & 64.103 & 0.0012 & 0.9992 \\
\hline
\end{tabular}



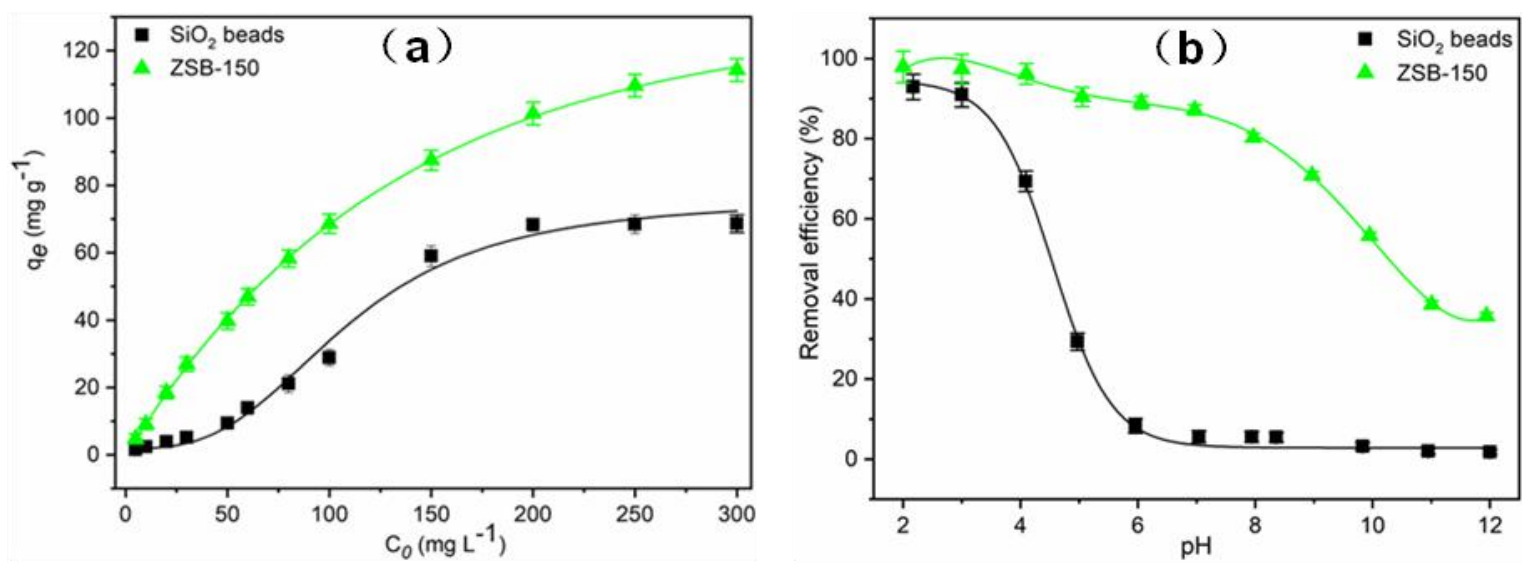

Figure 5. Aniline adsorption capacity(a) and Impact of $\mathrm{pH}$ on the aniline adsorption (b) of $\mathrm{SiO}_{2}$ and $\mathrm{ZSB}-150$ beads (adsorption time: $12 \mathrm{~h}$, adsorption temperature: $25^{\circ} \mathrm{C}, \mathrm{Co}: 20 \mathrm{mg} \mathrm{L}^{-1}$, adsorbent: $1 \mathrm{~g} \mathrm{~L}^{-1}$ ).

capacities at any time, $\mathrm{k}_{\mathrm{id}}$ is the intra-particle diffusion rate constant ( $\mathrm{mg} \mathrm{g}^{-1} \mathrm{~min}^{-1 / 2}$ ), and $\mathrm{C}$ is the thickness of boundary layer. The multi-linear plot reveals that the adsorption process containing several stages. Indeed, the data presented in Figure $4 \mathrm{~b}$ shows that the aniline adsorption occurred in three stages revealed by the three segment slopes in the scatter plot. The first linear portion, showing the fastest adsorption rate, is due to the transfer of the aniline molecules from the aqueous phase to the external surface of beads. The second slower step is related of the aniline diffusion in the intraparticle space, and the final linear portion is the result of diffusion through the micropore systems of ZSM-5 and the reaction with existing adsorption sites. This interpretation is in line with previously published data of adsorption of organic pollutants on porous materials. $^{48}$

The sorption of aniline on $\mathrm{SiO}_{2}$ and ZSB-150 beads as a function of the initial concentration was studied. As can be seen in Figure $5 a$, the adsorption capacities increase with the increase in aniline concentration, which is attributed to the incremental driving force caused by the initial concentration of adsorbate. The plato in the isotherm appears when the available adsorption sites are exhausted, i.e., the concentration of adsorbate exceeds the adsorption capacity of the adsorbent. The ZSB-150 beads showed a much remarkable uptake, and its adsorption isotherm reached a plato more delayed than $\mathrm{SiO}_{2}$ beads, which is attributed to a large number of active sites within zeolite micropores. In order to get deeper insights in the mechanism of aniline sequestration, the adsorption curves were fitted with the Langmuir (1), Freundlich (2) and Temkin models (3), ${ }^{49}$ according to the equations:

$\mathrm{C}_{\mathrm{e}} / \mathrm{q}_{\mathrm{e}}=1 / \mathrm{K}_{\mathrm{L}} \mathrm{q}_{\max }+\mathrm{C}_{\mathrm{e}} / \mathrm{q}_{\max }$

$\ln \mathrm{q}_{\mathrm{e}}=\ln \mathrm{K}_{\mathrm{F}}+1 / \mathrm{n} \ln \mathrm{C}_{\mathrm{e}}$

$\mathrm{q}_{\mathrm{e}}=\mathrm{RT} / \mathrm{b} \ln \mathrm{K}_{\mathrm{T}}+\mathrm{RT} / \mathrm{b} \ln \mathrm{C}_{\mathrm{e}}$

where $C_{e}$ is the residual concentration at equilibrium in solution $\left(\mathrm{mg} \mathrm{L}^{-1}\right) ; \mathrm{q}_{\mathrm{e}}$ is the amount adsorbed at equilibrium (mg $\left.\mathrm{g}^{-1}\right) ; \mathrm{q}_{\max }$ is the maximum adsorption capacity at equilibrium ( $\mathrm{mg} \mathrm{g}^{-1}$ ); and $\mathrm{K}_{\mathrm{L}}, \mathrm{K}_{\mathrm{F}}$ and $\mathrm{K}_{\mathrm{T}}$ are the corresponding constants, respectively. Analyses on the aniline adsorption isotherms by these three models are shown in Figure S8 and the fitted parameters summarized in Table 3 . The $R^{2}$ value of the Langmuir model shows the best fit for the aniline sorption on the ZSB-150 sample (with $\mathrm{R}^{2}$ of 0.9887 ), and the calculated maximum adsorption capacity is close to the experimental value. This result suggests that the adsorption of aniline on ZSB-150 could be modeled by monolayer adsorption. It reveals a highly uniform distribution of $\mathrm{ZSM}-5$ in the $\mathrm{SiO}_{2}$ matrix. The fitted models for the aniline adsorption on $\mathrm{SiO}_{2}$ and ZSB-150 beads could be interpreted on the basis of acid-base interactions and adsorption in micropore space. As mentioned, the silanol of $\mathrm{SiO}_{2}$ and ZSB-150 can form specific acid-base interactions with an

Table 3. Adsorption isotherm model parameters derived from the Langmuir, Freundlich and Temkin model

\begin{tabular}{|c|c|c|c|c|c|c|c|c|c|}
\hline \multirow[b]{2}{*}{ Adsorbents } & \multicolumn{3}{|l|}{ Langmuir } & \multicolumn{3}{|l|}{ Freundlich } & \multicolumn{3}{|l|}{ Temkin } \\
\hline & $\begin{array}{l}\mathrm{q}_{\max } \\
\left(\mathrm{mg} \mathrm{g}^{-1}\right)\end{array}$ & $\begin{array}{l}\mathrm{K}_{\mathrm{L}} \\
\left(\mathrm{L} \mathrm{mg}^{-1}\right)\end{array}$ & $\mathrm{R}_{\mathrm{L}}^{2}$ & $\begin{array}{l}\mathrm{K}_{\mathrm{F}}\left(\mathrm{mg} \mathrm{g}^{-1}\right) \\
\left(\mathrm{L} \mathrm{mg}^{-1}\right)^{1 / \mathrm{n}}\end{array}$ & $n$ & $\mathrm{R}_{\mathrm{F}}^{2}$ & $\begin{array}{l}\mathrm{K}_{\mathrm{T}} \\
\left(\mathrm{J} \mathrm{g}^{-1}\right)\end{array}$ & $\begin{array}{l}\mathrm{b} \\
\left(\mathrm{J} \mathrm{mol}^{-1}\right)\end{array}$ & $\mathrm{R}_{\mathrm{T}}^{2}$ \\
\hline $\mathrm{SiO}_{2}$ & 370.37 & 0.0012 & 0.3669 & 0.473 & 1.04 & 0.9923 & 0.1222 & 138.85 & 0.8177 \\
\hline ZSB-150 & 120.48 & 0.0626 & 0.9887 & 12.367 & 2.14 & 0.9704 & 2.0678 & 140.90 & 0.9352 \\
\hline
\end{tabular}



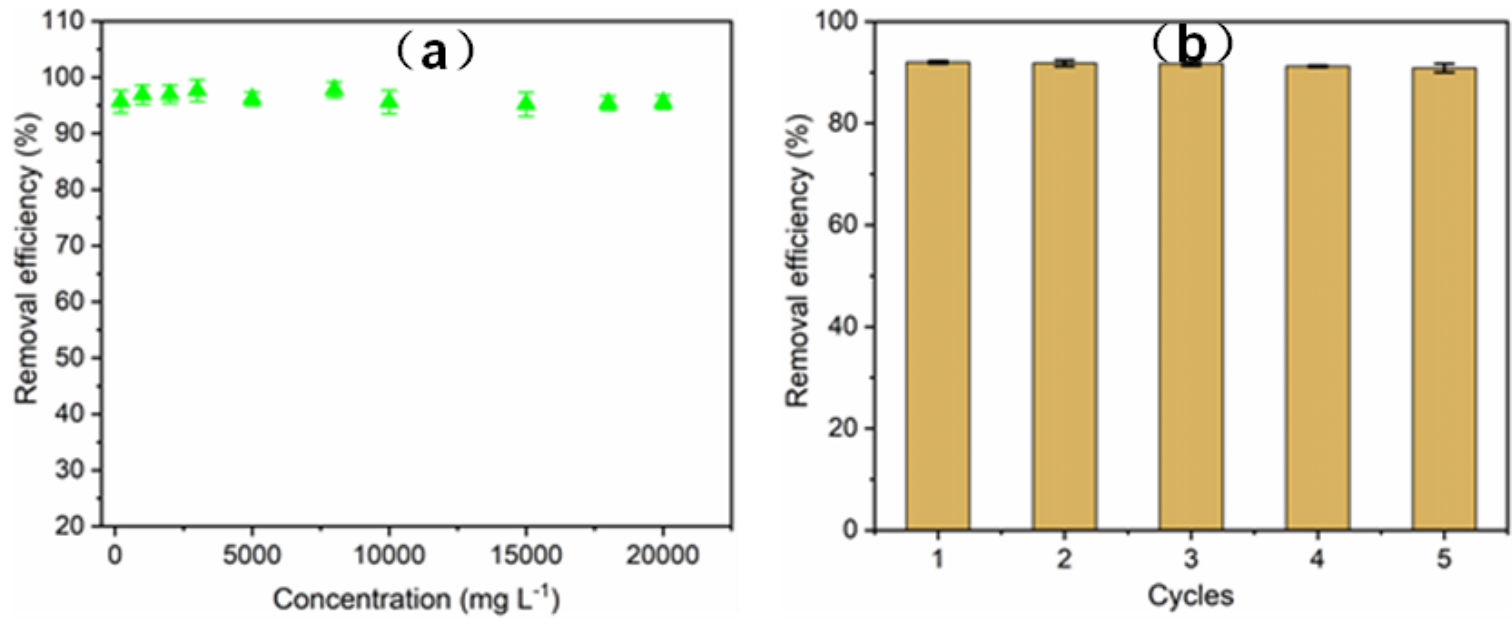

Figure 6. Effect of $\mathrm{NaCl}$ concentration (a) and Recyclability (b) on the aniline adsorption of ZSB-150 beads (adsorption time: $12 \mathrm{~h}$, adsorption temperature: $25^{\circ} \mathrm{C}, \mathrm{Co}: 20 \mathrm{mg} \mathrm{L}^{-1}$, adsorbent: $1 \mathrm{~g} \mathrm{~L}^{-1}$ ).

aniline molecule, while the additional confinement effect in zeolite micropores greatly enhances the adsorption performance.

The effect of $\mathrm{pH}$ on the aniline uptake is shown in Figure $5 b$. The aniline uptake is higher under acidic conditions with a maximum at $\mathrm{pH} \sim 3$. A gradual decrease of the aniline adsorption in the neutral and basic region is observed for ZSB150 as the lowest value is $36 \%$. In the case of $\mathrm{SiO}_{2}$ beads, a dramatic decrease of the adsorbed amount takes place at neutral $\mathrm{pH}$, which reaches the lowest value (ca. $1 \%$ ) at $\mathrm{pH}=$ 12. The fact that aniline adsorption is significantly dependent on $\mathrm{pH}$, is explained by the aniline state at different $\mathrm{pH}$ conditions. ${ }^{45,50}$ Aniline appears as aniline cation $\left(\mathrm{Ph}-\mathrm{NH}_{3}{ }^{+}\right)$ under acid condition, the sizes of ionized aniline are smaller than that in neutral conditions. So, the shape-selective adsorption of ZSM-5

Table 4. Comparison of the adsorption capacity of different sorbents used for aniline sequestration.

\begin{tabular}{lll}
\hline Adsorbent & $\begin{array}{l}\text { Adsorption capacity } \\
\left(\mathrm{mg} \mathrm{g}^{-1}\right)\end{array}$ & Ref. \\
\hline Modified diatomite & 43 & 42 \\
MCM-41 & 17 & 51 \\
Cu-Beta & 110 & 52 \\
Siliceous Zeolitic Material & 49 & 53 \\
Ca-Zeolitic Composites & 34 & 54 \\
graphitic carbon nitride & 66 & 9 \\
Electrospun PIM-1 fiber & 161 & 55 \\
$\begin{array}{l}\text { Poly acrylamide/SiO } \\
\text { Mesoporous silica nano- }\end{array}$ & 18 & 56 \\
spheres & 115 & Present \\
ZSB-150 & 52 & work \\
\hline
\end{tabular}

towards aniline gets enhanced. ${ }^{41}$ When $\mathrm{pH}$ gets more alkaline, acid-base interactions become ineffective due to the dissociation of silanols into $\mathrm{SiO}^{-}$. It is worth noting that, compared with the $\mathrm{SiO}_{2}$ beads, the adsorption capacity of ZSB150 is less impacted by the $\mathrm{pH}$ due to the additional confinement effect in zeolite micropores. Thus, the zeolite@silica composites show promising performance in the sequestration of aniline from an aqueous source in the neutral to a slightly acidic environment.

Sodium chloride, as a widespread inorganic salt, largely present in the waste water. Therefore, the impact of $\mathrm{NaCl}$ concentration on the aniline adsorption was studied. The concentrations of $\mathrm{NaCl}$ was ranged from 0 to $20000 \mathrm{mg} \mathrm{L}^{-1}$ at fixed aniline concentration $\left(\mathrm{C}_{0}=20 \mathrm{mg} \mathrm{L}^{-1}\right)$. As shown in Figure $6 a$, the efficiency of aniline removal remained almost constant at different $\mathrm{NaCl}$ concentrations.

The reusability is a crucial factor for the industrial perspective of an adsorbent. Recycling experiments were carried out under the initial concentration aniline of $20 \mathrm{mg} \mathrm{L}^{-1}$. The used beads were regenerated by shaking $10 \mathrm{mg}$ beads in $10 \mathrm{ml}$ ethanol solution, for $24 \mathrm{~h}$ and vacuum-dried at $60{ }^{\circ} \mathrm{C}$. The consecutive adsorption-desorption cycles were repeated five times, and the results for each adsorption process are presented in Figure $6 \mathrm{~b}$. The ZSB-150 beads maintain $90 \%$ adsorption capacity after 5 cycles. The integrity of the ZSB-150 adsorbent was checked after five adsorption-desorption cycles. As shown in Figure S9, the used ZSB-150 beads did not lose crystallinity and retained the spherical shape. Thus, the recyclability results show that ZSM-5@silica beads can withstand multiple uses in water purification.

The capacities toward aniline of most often used and efficient sorbents are presented in Table 4 and compared with the performance of ZSB-150. Composite ZSM-5@silica beads show remarkable capacity outpacing all silica-based adsorbents and modified zeolitic material. We attribute this to the result of the specific shaping technique that allows the preparation of binder-free sorbent of high adsorption efficiency. The high adsorption ability can also be ascribed to the well-defined microporous structure of zeolite with strong adsorption sites. Overall, the composite beads prepared by 
present work is a potential candidate to uptake aniline from aqueous media.

\section{Conclusions}

All-silica beads of size $300-400 \mu \mathrm{m}$ were prepared by using anion exchange resin as a macro template, followed by the combusting of the resin structure. The obtained all-silica beads were subjected to hydrothermal treatment in a ZSM- 5 yielding OSDA-free system. The resultant ZSM-5@silica composite retains the macro-morphological features of the ion exchange resin beads. The zeolite content and the secondary mesopore system of the composite beads were controlled by varying the synthesis temperature.

The obtained composite ZSM-5@silica beads were used for sequestration of aniline from aquous solutions. The composite obtained at $150{ }^{\circ} \mathrm{C}$ showed the highest aniline uptake. The results of the adsorption model showed that the adsorption processes fit well with the pseudo-second-order model and Langmuir isotherm model. This result was attributed to the substantial conversion of silica into ZSM- 5 and retained micromeso pore system, which favors the diffusion of the aniline.

It should be noted that the synthetic method developed in the present study offers a simple and green perspective of the preparation of zeolite-based adsorbents. The proposed method is expected to be applied for the preparation of other types zeolite-based composite materials.

\section{Conflicts of interest}

There are no conflicts to declare.

\section{Acknowledgements}

Q. F. and V. V. thank the National Natural Science Foundation of China (21571079, 21621001, 21390394, 21571076 and 21571078) for their financial support. This study was partially supported by the Sino-French International Associated Laboratory "Zeolites".

\section{Notes and references}

1 J. Li, C. Shi, H. Zhang, X. Zhang, Y. Wei, K. Jiang and B. Zhang, Silicalite-1 zeolite membrane: Synthesis by seed method and application in organics removal, Chemosphere, 2019, 218, 984-991.

2 R. P. Schwarzenbach, T. Egli, T. B. Hofstetter, U. von Gunten and B. Wehrli, Global Water Pollution and Human Health, Annual Review of Environment and Resources, 2010, 35, 109136.

3 N. Jiang, R. Shang, S. G. J. Heijman and L. C. Rietveld, Highsilica zeolites for adsorption of organic micro-pollutants in water treatment: A review, Water Res., 2018, 144, 145-161.

4 T. Han, C. Li, X. Guo, H. Huang, D. Liu and C. Zhong, In-situ synthesis of $\mathrm{SiO}_{2} @ \mathrm{MOF}$ composites for high-efficiency removal of aniline from aqueous solution, Appl. Surf. Sci., 2016, 390, 506-512.
5 J. O'Brien, T. F. O'Dwyer and T. Curtin, A novel process for the removal of aniline from wastewaters, J. Hazard. Mater., 2008, 159, 476-482.

$6 \mathrm{H}$. Koyuncu and A. R. Kul, Removal of aniline from aqueous solution by activated kaolinite: Kinetic, equilibrium and thermodynamic studies, Colloids Surf., A, 2019, 569, 59-66.

7 S. Ahmadi and C. A. Igwegbe, Adsorptive removal of phenol and aniline by modified bentonite: adsorption isotherm and kinetics study, Appl. Water Sci., 2018, 8.

8 T. M. Albayati and A. M. Doyle, Shape-Selective Adsorption of Substituted Aniline Pollutants from Wastewater, Adsorpt. Sci. Technol., 2013, 31, 459-468.

9 R. Hu, X. Wang, S. Dai, D. Shao, T. Hayat and A. Alsaedi, Application of graphitic carbon nitride for the removal of $\mathrm{Pb}$ (II) and aniline from aqueous solutions, Chem. Eng. J., 2015, 260, 469-477.

10 H. N. Tran, P. V. Viet and H. P. Chao, Surfactant modified zeolite as amphiphilic and dual-electronic adsorbent for removal of cationic and oxyanionic metal ions and organic compounds, Ecotoxicol. Environ. Saf., 2018, 147, 55-63.

11 R. Shaw, R. Sharma, S. Tiwari and S. K. Tiwari, Surface Engineered Zeolite: An Active Interface for Rapid Adsorption and Degradation of Toxic Contaminants in Water, ACS Appl. Mater. Interfaces, 2016, 8, 12520-12527.

12 N. M. Mahmoodi and M. H. Saffar-Dastgerdi, Zeolite nanoparticle as a superior adsorbent with high capacity: Synthesis, surface modification and pollutant adsorption ability from wastewater, Microchem. J., 2019, 145, 74-83.

13 S. Kundu, I. H. Chowdhury and M. K. Naskar, Hierarchical Porous Carbon Nanospheres for Efficient Removal of Toxic Organic Water Contaminants of Phenol and Methylene Blue, J. Chem. Eng. Data, 2018, 63, 559-573.

14 N. B. McGuinness, M. Garvey, A. Whelan, H. John, C. Zhao, G. Zhang, D. D. Dionysiou, J. A. Byrne and S. C. Pillai, Nanotechnology Solutions for Global Water Challenges, 2015, 1206, 375-411.

15 W. A. Khanday, M. Asif and B. H. Hameed, Cross-linked beads of activated oil palm ash zeolite/chitosan composite as a bioadsorbent for the removal of methylene blue and acid blue 29 dyes, Int. J. Biol. Macromol., 2017, 95, 895-902.

16 G. Rioland, L. Bullot, T. J. Daou, A. Simon-Masseron, G. Chaplais, D. Faye, E. Fiani and J. Patarin, Elaboration of FAUtype zeolite beads with good mechanical performances for molecular decontamination, RSC Adv., 2016, 6, 2470-2478.

17 J. Ding, L. Pu, Y. Wang, B. Wu, A. Yu, X. Zhang, B. Pan, Q. Zhang and G. Gao, Adsorption and Reduction of $\mathrm{Cr}(\mathrm{VI})$ Together with $\mathrm{Cr}$ (III) Sequestration by Polyaniline Confined in Pores of Polystyrene Beads, Environ. Sci. Technol., 2018, 52, 12602-12611.

18 D. M. Alzate-Sanchez, Y. Ling, C. Li, B. P. Frank, R. Bleher, D. H. Fairbrother, D. E. Helbling and W. R. Dichtel, betaCyclodextrin Polymers on Microcrystalline Cellulose as a Granular Media for Organic Micropollutant Removal from Water, ACS Appl. Mater. Interfaces, 2019, 11, 8089-8096.

19 K. Wang, F. Wang, F. Chen, X. Cui, Y. Wei, L. Shao and M. Yu, One-Pot Preparation of NaA Zeolite Microspheres for Highly Selective and Continuous Removal of $\mathrm{Sr}$ (II) from Aqueous Solution, ACS Sustainable Chem. Eng., 2018, 7, 2459-2470.

20 R. N. Putra and Y. H. Lee, Entrapment of micro-sized zeolites in porous hydrogels: Strategy to overcome drawbacks of zeolite particles and beads for adsorption of ammonium ions, Sep. Purif. Technol., 2020, 237, 116351.

21 A. Charkhi, M. Kazemeini, S. J. Ahmadi and S. Ammari Allahyari, Effect of Bentonite Binder on Adsorption and Cation Exchange Properties of Granulated Nano NaY Zeolite, Advanced Materials Research, 2011, 335-336, 423-428.

22 G. Rioland, H. Nouali, T. J. Daou, D. Faye and J. Patarin, Adsorption of volatile organic compounds in composite 
zeolites pellets for space decontamination, Adsorption, 2017, 23, 395-403.

23 E. R. Silva, J. M. Silva, M. F. Vaz, F. A. C. Oliveira and F. Ribeiro, Cationic polymer surface treatment for zeolite washcoating deposited over cordierite foam, Mater. Lett., 2009, 63, 572-574.

24 T. Fakin, A. Ristić, V. Mavrodinova and N. Zabukovec Logar, Highly crystalline binder-free ZSM-5 granules preparation, Microporous Mesoporous Mater., 2015, 213, 108-117.

25 K. Schumann, B. Unger, A. Brandt and F. Scheffler, Investigation on the pore structure of binderless zeolite $13 \times$ shapes, Microporous Mesoporous Mater., 2012, 154, 119123

26 M. B. Yue, N. Yang, W. Q. Jiao, Y. M. Wang and M.-Y. He, Drygel synthesis of shaped binderless zeolites composed of nanosized ZSM-5, Solid State Sci., 2013, 20, 1-7.

27 K. Moukahhal, T. J. Daou, L. Josien, H. Nouali, J. Toufaily, T. Hamieh, A. Galarneau and B. Lebeau, Hierarchical ZSM-5 beads composed of zeolite nanosheets obtained by pseudomorphic transformation, Microporous Mesoporous Mater., 2019, 288, 109565.

28 Z. You, G. Liu, L. Wang and X. Zhang, Binderless nano-HZSM-5 zeolite coatings prepared through combining washcoating and dry-gel conversion (DGC) methods, Microporous Mesoporous Mater., 2013, 170, 235-242.

29 V. Valtchev, Preparation of regular macroporous structures built of intergrown silicalite-1 nanocrystals, J. Mater. Chem. 2002, 12, 1914-1918.

30 E. P. Ng, D. Chateigner, T. Bein, V. Valtchev and S. Mintova, Capturing ultrasmall EMT zeolite from template-free systems, Science, 2012, 335, 70-73.

31 N. Ren, J. Bronić, B. Subotić, X.-C. Lv, Z.-J. Yang and Y. Tang Controllable and SDA-free synthesis of sub-micrometer sized zeolite ZSM-5. Part 1: Influence of alkalinity on the structural, particulate and chemical properties of the products, Microporous Mesoporous Mater., 2011, 139, 197206.

32 N. Ren, J. Bronić, B. Subotić, Y.-M. Song, X.-C. Lv and Y. Tang, Controllable and SDA-free synthesis of sub-micrometer sized zeolite ZSM-5. Part 2: Influence of sodium ions and ageing of the reaction mixture on the chemical composition, crystallinity and particulate properties of the products, Microporous Mesoporous Mater., 2012, 147, 229-241.

33 Q. Wu, X. Wang, G. Qi, Q. Guo, S. Pan, X. Meng, J. Xu, F. Deng, F. Fan, Z. Feng, C. Li, S. Maurer, U. Muller and F. S. Xiao, Sustainable synthesis of zeolites without addition of both organotemplates and solvents, J. Am. Chem. Soc., 2014, 136, 4019-4025.

34 M. D. Oleksiak, K. Muraoka, M. F. Hsieh, M. T. Conato, A. Shimojima, T. Okubo, W. Chaikittisilp and J. D. Rimer, Organic-Free Synthesis of a Highly Siliceous Faujasite Zeolite with Spatially Biased Q(4) (nAl) Si Speciation, Angew. Chem. Int. Ed. Engl., 2017, 56, 13366-13371.

35 L. Tosheva, V. Valtchev and J. Sterte, Amorphous very high surface area silica macrostructures, J. Mater. Chem., 2000, 10, 2330-2337.

$36 \mathrm{M}$. Smaihi, O. Barida and V. Valtchev, Investigation of the Crystallization Stages of LTA-Type Zeolite by Complementary Characterization Techniques, Eur. J. Inorg. Chem., 2003, 2003, 4370-4377.

37 W. S. F. Scheffler, D. Freude, H. Liu, W. Heyer, F. Janowski, Transformation of porous glass beads into MFI-type containing beads, Microporous Mesoporous Mater., 2002, 55, 181-191.

38 M. H. I. S. Mintova, V. Valtchev, B. Mihailova, Y. Bouizi and T. Bein, Closely Packed Zeolite Nanocrystals Obtained via Transformation of Porous Amorphous Silica, Chem. Mater. 2004, 16, 5452-5459.
39 D. J. de Ridder, J. Q. J. C. Verberk, S. G. J. Heijman, G. L. Amy and J. C. van Dijk, Zeolites for nitrosamine and pharmaceutical removal from demineralised and surface water: Mechanisms and efficacy, Sep. Purif. Technol., 2012, 89, 71-77.

40 A. Rossner, S. A. Snyder and D. R. Knappe, Removal of emerging contaminants of concern by alternative adsorbents, Water Res., 2009, 43, 3787-3796.

41 X. Guo, H. Yun, M. Zhang, Q. Li, Q. Zhou, H. Shao, W. Hu, C. Li and S. Fan, Adsorption of Low-Molecular-Weight Amines in Aqueous Solutions to Zeolites: An Approach to Impeding Low-Molecular-Weight Amines from Regenerating N-Nitrosamines, Ind. Eng. Chem. Res., 2017, 56, 1202412031

42 L. Jiang, L. Liu, S. Xiao and J. Chen, Preparation of a novel manganese oxide-modified diatomite and its aniline removal mechanism from solution, Chem. Eng. J., 2016, 284, 609-619.

43 K. Ueno, H. Negishi, T. Okuno, T. Saito, H. Tawarayama, S. Ishikawa, M. Miyamoto, S. Uemiya, Y. Sawada and Y. Oumi, A simple secondary growth method for the preparation of silicalite-1 membrane on a tubular silica support via gel-free steam-assisted conversion, J. Membr. Sci., 2017, 542, 150158.

44 K. Ueno, H. Negishi, T. Okuno, T. Saito, H. Tawarayama, S. Ishikawa, M. Miyamoto, S. Uemiya, Y. Sawada and Y. Oumi, High-performance silicalite-1 membranes on porous tubular silica supports for separation of ethanol/water mixtures, Sep. Purif. Technol., 2017, 187, 343-354.

45 H. Zheng, D. Liu, Y. Zheng, S. Liang and Z. Liu, Sorption isotherm and kinetic modeling of aniline on $\mathrm{Cr}$-bentonite, $J$. Hazard. Mater., 2009, 167, 141-147.

$46 \mathrm{H}$. Al-Johani and M. Abdel Salam, Kinetics and thermodynamic study of aniline adsorption by multi-walled carbon nanotubes from aqueous solution, J. Colloid Interface Sci., 2011, 360, 760-767.

47 M. Jovanovic, Z. Grbavcic, N. Rajic and B. Obradovic, Removal of $\mathrm{Cu}(\mathrm{II})$ from aqueous solutions by using fluidized zeolite $A$ beads: Hydrodynamic and sorption studies, Chem. Eng. Sci., 2014, 117, 85-92.

48 R. Zhao, T. Ma, S. Zhao, H. Rong, Y. Tian and G. Zhu, Uniform and stable immobilization of metal-organic frameworks into chitosan matrix for enhanced tetracycline removal from water, Chem. Eng. J., 2019, 382,122893.

49 P. He, K.-G. Haw, J. Ren, Q. Fang, S. Qiu and V. Valtchev, MOF-cation exchange resin composites and their use for water decontamination, Inorg. Chem. Front., 2018, 5, 27842791.

50 Z. Liang, W. Shi, Z. Zhao, T. Sun and F. Cui, Enhanced removal and adsorption characters of aniline by the inorganically modified mesoporous silica nano-spheres, Colloids Surf., $A$, 2017, 513, 250-258.

51 X. Yang, Q. Guan and W. Li, Effect of template in MCM-41 on the adsorption of aniline from aqueous solution, J. Environ. Manage., 2011, 92, 2939-2943.

52 T. C. a. T. F. O. D. J. O'Brien, An Investigation into the Adsorption of Aniline from Aqueous Solution Using H-Beta Zeolites and Copper-exchanged Beta Zeolites, Adsorpt. Sci. Technol., 2004, 23 255-266.

53 B. A. Shah, A. A. Abebe and A. V. Shah, MicrowaveSynthesized Barium-Impregnated Siliceous Zeolitic Material Derived from Bagasse Fly Ash for Uptake of Aniline, Arabian J. Sci. Eng., 2016, 42, 139-152.

54 B. A. Shah, O. A. Oluyinka and A. V. Shah, Fly Ash Reuse as Mesoporous Ca- and Mg-Zeolitic Composites for the Seclusion of Aniline from Aqueous Solution, Arabian J. Sci. Eng., 2018, 44, 289-304. 
55 B. Satilmis and T. Uyar, Removal of aniline from air and water by polymers of intrinsic microporosity (PIM-1) electrospun ultrafine fibers, J. Colloid Interface Sci., 2018, 516, 317-324.

56 F. An, X. Feng and B. Gao, Adsorption of aniline from aqueous solution using novel adsorbent $\mathrm{PAM} / \mathrm{SiO}_{2}$, Chem. Eng. J., 2009, 151, 183-187. 